\title{
LAS PERCEPCIONES DE LOS PROFESORES RESPECTO A LA INVESTIGACIÓN E INNOVACIÓN EN SUS CONTEXTOS PROFESIONALES
}

TEACHERS' PERCEPTIONS ON RESEARCH AND INNOVATION IN THEIR PROFESSIONAL CONTEXTS

\author{
Volumen 15, Número 2 \\ Mayo - Agosto \\ pp. 1-30
}

\author{
Claudio Díaz Larenas \\ María Inés Solar \\ Valentina Soto Hernández \\ Marianela Conejeros Solar
}

Revista indizada en REDALYC, SCIELO

Revista distribuida en las bases de datos:

CATÁLOGO DE LATINDEX, IRESIE, CLASE, DIALNET, DOAJ, E-REVIST@S, SHERPA/ROMEO, QUALIS, MIAR

Revista registrada en los directorios:

ULRICH'S, REDIE, RINACE, OEI, MAESTROTECA, PREAL, CLACSO 


\title{
LAS PERCEPCIONES DE LOS PROFESORES RESPECTO A LA INVESTIGACIÓN E INNOVACIÓN EN SUS CONTEXTOS PROFESIONALES TEACHERS' PERCEPTIONS ON RESEARCH AND INNOVATION IN THEIR PROFESSIONAL CONTEXTS
}

\author{
Claudio Díaz Larenas ${ }^{1}$ \\ María Inés Solar? \\ Valentina Soto Hernández $z^{3}$ \\ Marianela Conejeros Solar ${ }^{4}$
}

Resumen: El propósito de este artículo es analizar procesos de formación asociados a la capacidad para desarrollar investigación, innovación educativa, espacios de liderazgo y comunicación interna, y vinculación escuela-familia en establecimientos educacionales de Chile. La muestra se constituyó de 108 docentes de preescolar, educación básica y media, pertenecientes a establecimientos públicos, semi-públicos y particulares de la Región del Biobio en Chile. La investigación es de tipo cuantitativo transeccional, con un diseño de carácter correlacional. Para recolectar la información se utilizó la técnica de la encuesta y el análisis de datos se realizó mediante conglomerados jerárquicos. Los resultados muestran que los profesores encuestados no consideran que la investigación sea parte de sus prácticas docentes. A pesar de que gran parte de los docentes reconocen realizar innovaciones, son percibidas como una instancia aislada, desvinculadas del liderazgo directivo. Los hallazgos además indican que los docentes ejercen liderazgo a nivel pedagógico y directivo. La comunicación interna es valorada positivamente por los docentes, sin embargo, la vinculación entre escuela y familia es débil. $A$ nivel de formación continua, los docentes consideran que las instancias de perfeccionamiento no promueven el desarrollo personal.

Palabras clave INVESTIGACIÓN EDUCATIVA, INNOVACIÓN EDUCATIVA, COMUNICACIÓN, LIDERAZGO, FORMACIÓN DOCENTE, CHILE.

\begin{abstract}
The aim of this study is to analize teacher preparation processes associated to the capacity to develop research, pedagogical innovation, leadership spaces and internal communication, and the relationship between school and family in Chilean educational establishments. The sample was made up by 108 nursery, primary and secondary school teachers from public, semi public and private schools in Chile. This is a quantitative crosssectional study with a non experimental correlational research design. To collect the data the survey technique was used and a hierarchical cluster analysis was later applied. The results show that the surveyed teachers do not regard research as part of their teaching practices. Even though the majority of teachers admit to conduct innovations, these are perceived to be isolated instances, which are not linked to management leadership. The findings also indicate that teachers exert leadership at pedagogical and management levels.

Internal communication is also highly valued by teachers, however, the relationship between school and family is weak. At continuing education level, teachers consider that training instances do not promote personal development.
\end{abstract}

Key words EDUCATIONAL RESEARCH, EDUCATIONAL INNOVATION, COMMUNICATION, LEADERSHIP, TEACHER EDUCATION, CHILE.

\footnotetext{
${ }^{1}$ Universidad de Concepción, Chile. Doctor en Educación. Dirección Electrónica: claudiodiaz@udec.cl

2 Universidad de Concepción, Chile Doctora en Filosofía y Ciencias de la Educación. Dirección Electrónica: marsolar@udec.cl

3 Universidad de Concepción, Chile. Magíster en Sociología. Dirección Electrónica: $\underline{\text { sotohernandez.valentina@gmail.com }}$

${ }^{4}$ Dirección de Educación Continua. Universidad de Concepción, Chile. Magíster en Educación. Dirección Electrónica: conejerosmarianela@gmail.com
}

Artículo recibido: $1^{\circ}$ de setiembre, 2014

Enviado a corrección: 24 de febrero, 2015

Aprobado: 23 de marzo, 2015 


\section{Introducción}

Las transformaciones políticas, sociales y económicas de la sociedad impactan en las escuelas y los profesores, a través de nuevas demandas que no solo se conforman a nivel de aula, sino de la formación de los docentes. De acuerdo a Pérez Gómez (2010) exige al profesorado formar:

ciudadanos capaces de entender la complejidad de situaciones y el incremento exponencial de la información, así como de adaptarse creativamente a la velocidad del cambio y a la incertidumbre que le acompaña [...] ante tales demandas, la figura del docente como catalizador de los procesos de enseñanza-aprendizaje se sitúa en el eje de atención y polémica. Si la escuela tiene que responder a nuevas y complejas exigencias, la formación de los docentes ha de afrontar retos similares para responder a tan importantes y novedosos desafíos (p. 38).

En este contexto, la formación docente permanente es fundamental para el desarrollo de los procesos educativos. La sociedad "exige de los profesionales una permanente actividad de formación y aprendizaje" (Marcelo, 2009). De acuerdo a Vezub (2007) "los docentes se enfrentan al desafío de apropiarse de nuevas claves de interpretación y acción que les posibiliten su desempeño en contextos escolares heterogéneos, con diversos problemas sociales y culturales" (p. 14).

En Chile, la formación inicial y continua, así como el desarrollo docente se ha instalado en el debate público desde hace varios años. Desde la investigación educativa, Cisternas (2011) plantea que las investigaciones sobre formación docente, realizadas entre 1997 y 2006, han sido realizadas mediante tres ejes: a) los actores que participan en la formación; b) los dispositivos que constituyen el currículo; y c) los conocimientos vinculados a la formación. La investigación realizada aquí se enmarca en la primera temática, profundizando en las percepciones de las prácticas del aula y la formación de uno de los actores clave: los docentes en ejercicio. El estudio se inició con la pregunta: ¿cuáles son las percepciones de los docentes respecto a la investigación, innovación, liderazgo y comunicación en su contexto educativo? Para responder a esta interrogante, el objetivo general de este estudio es relacionar la percepción de los docentes respecto de los procesos de formación asociados a la capacidad para desarrollar investigación, innovación educativa, espacios de liderazgo y comunicación interna/ vinculación escuela-familia. Para ello, se analiza la percepción docente a partir de los siguientes objetivos específicos: a) clasificar los procesos 
según agrupamiento de conglomerados jerárquicos, y b) analizar cada conglomerado de acuerdo a cuatro variables: género, formación académica, nivel educativo en el que ejercen su docencia y edad.

Este artículo se inserta en el proyecto "Acciones Integradas para el Fortalecimiento Científico e Institucional" de la "Red de investigación e innovación educativa para la mejora de la educación A2/039772/11 patrocinado por AECID (España) y liderado por la Universidad de Oviedo (España) con la participación de Pontificia Universidad Católica de Valparaíso; Universidad de Concepción; Universidad Austral; Universidad de Talca. Se circunscribe además en el marco del proyecto FONDECYT 1120247 "Investigación del conocimiento profesional, las creencias implícitas y el desempeño en aula de estudiantes de Pedagogía en Inglés como estrategia de generación de indicadores de monitoreo de su proceso formativo".

Este artículo se encuentra estructurado del siguiente modo. Luego de la introducción, se presenta un breve referente teórico, que abordará el concepto de percepción, en seguida, se definen los temas abordados en el estudio: investigación e innovación docente, comunicación y liderazgo escolar, y perfeccionamiento docente. En el siguiente apartado, se presenta la metodología utilizada, donde se detallan los cluster y sus respectivas categorías. Después, se analizan los resultados por cluster mediante las variables de género, formación académica, nivel educacional donde ejerce docencia y edad. Finalmente, en el último apartado, además de las conclusiones, se presentan algunas recomendaciones.

\section{Breve referente teórico}

El concepto de percepción y percepción social ha sido desarrollado desde la psicología social. De acuerdo a Baron y Byrne (2005) la percepción social es el proceso por el cual buscamos conocer y comprender a otras personas. Para Vander Zanden (1990) la percepción también puede referirse a la comprensión de los fenómenos sociales en tanto fenómenos de relación entre individuos y sociedad. Esta última definición permite estudiar a las personas y grupos frente a fenómenos complejos e interconectados con otros fenómenos sociales. En este estudio, se utilizó el concepto de percepción social como base para comprender fenómenos vinculados a la formación docente y a las prácticas docentes en el aula, que a continuación se pasará a detallar. 


\subsection{Investigación e innovación docente}

La investigación educativa realizada en el aula ha sido propuesta como una estrategia beneficiosa para las prácticas pedagógicas ya que favorece la incorporación de nuevas metodologías. En efecto, Magendzo (2000) afirma que la investigación apunta a un nuevo rol del profesor como constructor del conocimiento, quien "puede y debe elaborar teoría desde la práctica [...] eliminando la disociación que tradicionalmente se ha planteado entre teoría y práctica". Este proceso recibe la denominación de teorización práctica "practical theorizing" (Hagger y Hazel, 2006, citados en Pérez Gómez, 2010) y es concebido también como "la relación entre experiencia y saber, como el saber que emerge de la propia experiencia pensada" (Contreras, 2010, citado en Pérez Gómez, 2010).

Al recopilar evidencias sobre el desarrollo de su propia enseñanza en un contexto concreto, el docente puede problematizar las teorías implícitas, creencias, valores, y artefactos que configuran su práctica y desarrollar procesos sistemáticos de generación y comprobación de hipótesis y alternativas de acción sobre cómo desarrollar cambios e innovaciones valiosas. (Pérez Gómez, 2010, p. 47)

Los avances en educación están estrechamente vinculados a la innovación y a la investigación. Rodríguez y Castañeda (2001) señalan que los docentes se asocian a los principales factores que dinamizan el cambio educativo ya que "son los actores de las prácticas pedagógicas innovadoras, con sus experiencias y reflexiones, quienes propician la aparición de nuevas teorías pedagógicas, el descubrimiento de nuevos modelos y métodos pedagógicos y la concepción de nuevas políticas y reformas educativas” (p.88).

En Chile, la formación de los profesores intenta responder a las políticas educativas y perfila un nuevo papel del profesor caracterizado por:

La construcción de una parte importante del currículum escolar, el trabajo colectivo [...] y la autonomía en el proceso educativo [tareas que exigen] una reconceptualización de la formación de los profesores, teniendo en consideración una valoración de la acción pedagógica como fuente de conocimientos y habilidades [y el] desarrollo sostenido de la investigación educacional. (Rodríguez, 1997, citado en Rodríguez y Castañeda, 2001, p. 120)

Si bien parece evidente que la investigación es la base de la generación de conocimiento, Imbernón (2011) plantea que "en el campo educativo la fractura entre la teoría 
y la práctica, entre la investigación y la aplicación, ha sido históricamente abismal” (p. 7). Esto ocurre, principalmente, porque "la educación no es una actividad teórica, sino una actividad práctica relacionada con el cometido general de desarrollar las mentes de los alumnos" Carr (1996). La educación se asemeja a las prácticas teóricas debido a que es una actividad intencional, desarrollada en un marco de pensamiento que da sentido a las prácticas pedagógicas y a lo que se intenta lograr con ellas.

De acuerdo a Clark y Peterson (1989), el profesorado es un mediador cognitivo de las ideas y propuestas educativas, así como un interpretador dinámico de su propia realidad docente.

En palabras de Rodríguez y Castañeda (2001), la investigación puede ser considerada "el alimento intelectual del quehacer educativo y pedagógico", sin cuyos aportes "las innovaciones carecerían de fundamentos teóricos y de orientación conceptual".

Por otra parte, para Ezpeleta (2004), la innovación tiene mayor probabilidad de éxito y arraigo cuando surge de la propia escuela, aunque sus posibilidades de generalización son limitadas; cuando la innovación es inducida (por ejemplo, una reforma), tendrá una mayor generalización, pero habrá una mayor tendencia a resistirla por parte de los actores escolares.

La idea de que una innovación tendrá éxito si es bien explicada y si los docentes son convenientemente adiestrados suponía una falta de entendimiento respecto a las complejidades de los procesos de enseñanza y de las dinámicas sociales en las que éstos están insertos. (Contreras, 1996, p. 92)

A medida que se han desarrollado enfoques de comprensión de las innovaciones más culturales o políticos (Angulo, 1990; House, 1988; Pudduck, 1991 citados por Contreras 1996, p. 93), "se ha empezado a aceptar que la dinámica de una innovación no puede entenderse como la plasmación en la realidad de lo que está en la mente de políticos o expertos" (Gimeno, 1992, citado por Contreras, 1996).

Al final de todo este proceso "la escuela, que es el centro neurálgico de la mejora escolar y los docentes, ejes del proceso de enseñanza y aprendizaje" (Fullan, 1993; Reynolds, 1997, citado en Cornejo 2006, p.121). Cornejo (2006, p. 126) señala que "lo concreto es que el sistema educativo chileno, en la práctica, ha mostrado una muy baja capacidad de innovación [...] es condición necesaria fortalecer la organización y participación 
de los actores educativos (docentes, alumnos y apoderados) para llevar a cabo los procesos de mejora e innovación educativa".

Frente a la investigación e innovación educativa, los profesores en ejercicio tienen mucho que aportar. Así las percepciones docentes proporcionan información importante acerca de cómo se insertan la investigación y la innovación en los establecimientos educacionales, cuáles son sus fortalezas y debilidades y cómo el docente se sitúa frente a estos temas.

A pesar de que los docentes no son responsables únicos de los resultados y de la calidad del sistema educativo tampoco pueden asumir el desafío del cambio en forma aislada e individual, sin embargo tienen un rol protagónico en la configuración de las experiencias de aprendizaje de los alumnos. (Vezub, 2007, p. 5)

En relación a la innovación, debe tenerse presente además que la visión de los docentes surge de sus experiencias individuales y colectivas insertas en un contexto en particular.

La innovación ocurre en algún espacio educativo, un centro, una institución, un departamento administrativo, un aula, un cuerpo académico. [...] el contexto donde ocurre la innovación, con su cultura, su clima, sus resistencias, es uno de los factores que se han revelado como más influyentes en el éxito de una innovación educativa. El contexto es tan determinante que lo que en uno puede ser innovador, en otro, no lo es, estableciendo el carácter mismo de innovación de una experiencia. Así mismo, el contexto influye fuertemente en la viabilidad de una innovación. (Ortega, Ramírez, Torres, López, Servín, Suárez y Ruiz, 2012, p. 163).

\subsection{Comunicación y liderazgo escolar}

La comunicación en la escuela es un factor tan relevante como complejo. Incorpora las relaciones establecidas tanto al interior del aula, entre el profesor y sus alumnos, como fuera del aula, entre los distintos actores de la comunidad escolar. De esta forma, la comunicación en el seno escolar requiere que el profesor no solo sea capaz de comunicarse eficazmente, sino que ejerza su liderazgo (Imbernón, 2012).

El enfoque cultural del cambio para la mejora de la escuela ha otorgado cada vez más relevancia al papel del liderazgo. De acuerdo a González (1997), "el líder se mueve en un marco de valores, propósitos y creencias que representan la cultura de la organización y 
desde la cual puede ir impulsando, cultivando y sosteniendo los proyectos y esfuerzos de la organización" Para que esto se pueda concretar es necesario que el líder comprenda a su organización, en palabras de Fullan y Hargreaves (1997): "los líderes necesitan comprender la cultura de su organización antes de poder dirigir adecuadamente la organización y la propia cultura".

Leithwood et al. (2006, p. 45), citado en Bolívar (2010), se refieren al liderazgo como:

La capacidad de ejercer influencia sobre otras personas, de manera que éstas puedan tomar las líneas propuestas como premisa para su acción. Esta influencia, no basada en el poder o autoridad formal, se puede ejercer en distintas dimensiones, especialmente en el plano organizativo, cuando una dirección logra alcanzar consenso y moviliza a la organización en torno a metas comunes.

El liderazgo educativo o pedagógico se produce en la medida que las trasformaciones son encaminadas al mejoramiento del aprendizaje de los estudiantes (Bolívar, 2010, p. 20).

El informe TALIS (OCDE, 2009) señala que no hay oposición entre un modelo administrativo y otro pedagógico: los directores que ejercen un destacado liderazgo pedagógico son, en general, los que también ejercen mejor el liderazgo administrativo. En Chile esto parece constatarse, como muestra el informe (Carbone, 2008) sobre la situación del liderazgo escolar, en el que se mantiene la hipótesis de que dicho liderazgo se vehiculiza a través de los dispositivos de gestión, como modo para impactar en los aprendizajes de los alumnos. Sin embargo, es cierto, que la sobrecarga de actividades burocráticas-administrativas impide el ejercido de un liderazgo pedagógico. (Weinstein, 2009, citado en Bolívar, 2010)

Diversos investigadores señalan que entre todos los factores internos de la escuela, después de la labor del profesorado en el aula, el liderazgo es el segundo factor más relevante en los logros de aprendizaje de los estudiantes (Informe McKinsey Barber y Mourshed, 2007 y OCDE, 2009; Pont, Nusche y Moorman, 2008 Waters Marzano y McNulty, 2003; Leithwood y Jantzi, 2008; Leithwood, et al. 2004, Robinson, 200, citados en Bolívar, 2010).

Las acciones orientadas a crear y sostener una cultura profesional colaborativa, se cuentan como una de las prácticas claves de un liderazgo efectivo, las que además deben 
involucrar a otros agentes de la comunidad dado el carácter vinculante de la escuela como institución social.

Para Anderson (2010), el rediseño de la organización no abarca solamente la organización interna de la escuela, sino también la búsqueda de cómo involucrar de una mejor manera a los padres de familia (y otros agentes de la comunidad) para apoyar el aprendizaje de los estudiantes, y también para contribuir al proyecto de mejora escolar.

La escuela como institución social debe demostrar y materializar su carácter vinculante con el contexto en el cual se inserta y desarrolla su labor, es reconocida la importancia de esta interacción para dar cabida y asumir un rol protagónico en el desarrollo de las comunidades con las cuales se vincula. Desde esta perspectiva Imbernón (2011, p. 7):

Para que la institución educativa eduque realmente en la vida y para la vida debe tener un carácter más relacional, más cultural-contextual y comunitario, en cuyo ámbito adquiere importancia la interacción entre todas las personas vinculadas, ya sea por su trabajo en ella como en su condición de usuario, de agente social, o de simple miembro de la comunidad.

En esta misma línea, Rodríguez y Ríos (2007), citado en Tapia-Gutiérrez, BecerraPeña, Mansilla-Sepúlveda, Saavedra-Muñoz (2011), se refieren a la necesidad que manifiestan los establecimientos educacionales de vincularse con la familia, "la cual es una de las principales dificultades a las que se enfrentan, sobre todo en contextos vulnerables", esto da cuenta de la existencia de un "reconocimiento de las características socioculturales de las familias, pero se hace latente la necesidad de contar con un diagnóstico y puesta en práctica de estrategias que garanticen un espacio favorable de interacción y comunicación”.

Por otra parte, Rivera y Milicic (2006) citado en Tapia, et al. (2011), proponen "que es necesario reconstruir la creencia de la relación familia-escuela, identificar las competencias, el perfil de los padres, reconocer sus demandas para lograr su acercamiento, que fructifique en la interacción en pos de los estudiantes".

\subsection{Formación permanente y desarrollo personal}

Actualmente se hace alusión con mucha frecuencia a los conceptos de desarrollo profesional del profesorado. El desarrollo profesional no se constituye únicamente por el perfeccionamiento de conocimientos y habilidades, sino que también considera las creencias 
y actitudes existentes respecto a la capacidad de asumir responsabilidades y expectativas sobre el trabajo (Anderson, 2010).

De acuerdo a Imbernón (2011) no es posible afirmar que el desarrollo profesional del profesorado se asocie solamente al desarrollo pedagógico, cognitivo y teórico, sino que además se debe considerar las condiciones laborales e institucionales que finalmente es la que permite o impide el desarrollo de una carrera docente. En este contexto intervienen los diversos marcos escolares en los que se produce el desarrollo profesional.

Diversos autores (Fullan, 2005; Togneri y Anderson, 2003 citado en Anderson, 2010) "destacan la importancia de que el aprendizaje permanente de los profesores se realice de manera contextualizada, inserto en el lugar donde trabajan, y alineado con las metas de mejoramiento y con la resolución de los problemas que impiden la mejora".

En esta misma línea, y para clarificar el término de desarrollo profesional y su vinculación con la investigación y la gestión, Imbernón (2011) afirma que "por tanto, un posible acercamiento al concepto de desarrollo profesional del profesorado puede ser el de cualquier intento sistemático de mejorar la práctica laboral, creencias y conocimientos profesionales, con el propósito de aumentar la calidad docente, investigadora y de gestión" (p. 5).

Hay que abandonar el obsoleto concepto de que la formación es la actualización científica didáctica y psicopedagógica del profesorado por un concepto que la formación debe ayudar a descubrir la teoría, ordenarla, fundamentarla, revisarla y construirla este concepto parte de la base de que el profesorado es constructor de conocimiento pedagógico de forma individual y colectiva y, por tanto, partícipe activo de su desarrollo profesional. (Imbernón, 2011, p. 15)

El desarrollo de personas como componente del mejoramiento escolar puede comprenderse como el perfeccionamiento de conocimientos y habilidades que ayudan a los docentes a realizar de mejor manera su labor. Michael Fullan (2005), citado en Anderson (2010), señala que "en una organización caracterizada por un desempeño efectivo, hay un aprendizaje continuo de los miembros. Este aprendizaje puede consistir en identificar y corregir errores que se cometen habitualmente o en descubrir nuevas maneras de hacer el trabajo". 


\section{Metodología}

La presente investigación es de tipo cuantitativo con un diseño transeccional, debido a que se analizó la información proveída por los sujetos en un solo momento (Hernández, Fernández y Baptista, 2008). El objetivo general de la investigación es relacionar la percepción de los docentes respecto de los procesos de formación asociados a la capacidad para desarrollar investigación e innovación educativa. Los objetivos específicos son: I) clasificar la percepción docente según conglomerados jerárquicos, e II) analizar cada conglomerado de acuerdo a cuatro variables: género, formación académica, nivel educativo en el que ejercen su docencia y edad.

La muestra de investigación fue de carácter intencional, ya que se realizó una selección deliberada de los sujetos de estudio. Se constituyó de 108 docentes pertenecientes a establecimientos públicos, particulares subvencionados y particulares de la región del Bío Bío, Chile. En la Tabla 1 se describe la muestra de estudio según sexo y nivel educativo en el que habitualmente se ejerce docencia.

\section{Tabla 1}

Muestra de estudio según sexo y nivel educativo en el que se ejerce la docencia

\begin{tabular}{|l|l|l|l|l|l|l|}
\hline & $\begin{array}{l}\text { Educación } \\
\text { Preescolar }\end{array}$ & $\begin{array}{l}\text { Primero a } \\
\text { cuarto básico }\end{array}$ & $\begin{array}{l}\text { Quinto a octavo } \\
\text { básico }\end{array}$ & $\begin{array}{l}\text { Enseñanza } \\
\text { media CH }\end{array}$ & $\begin{array}{l}\text { Enseñanza } \\
\text { media TP }\end{array}$ & Total \\
\hline Hombre & 0 & 2 & 10 & 6 & 5 & 23 \\
\hline Mujer & 10 & 20 & 31 & 15 & 9 & 85 \\
\hline Total & 10 & 22 & 41 & 21 & 14 & 108 \\
\hline & & & & & & \\
\hline
\end{tabular}

Para recolectar la información se utilizó la técnica de la encuesta, con el fin de conseguir mediciones cuantitativas sobre una gran cantidad de características objetivas y subjetivas a una muestra de sujetos de la población. Para medir la percepción de los docentes, las preguntas se formularon a través de una Escala Likert, la cual considera la intensidad de la expresión de la actitud. Para construir una escala de este tipo, lo primero fue diseñar una serie de ítems relevantes del tipo de actitud/es que se quiere medir. Luego, se asignan puntajes a los ítems según la dirección positiva o negativa de este (Aravena, Kimelman, Micheli, Torrealba y Zúñiga, 2006).

Para realizar el análisis de la información, se aplicaron estadísticas descriptivas, las cuales se refieren a la tarea de describir los datos, valores o puntuaciones obtenidas para cada variable. Este proceso incluyó análisis de distribución de frecuencias, medidas de tendencia central y medidas de dispersión. 
Para realizar la categorización de los ítems del cuestionario se efectuaron análisis de correlación, a través de la aplicación de la prueba no paramétrica RHO de Spearman.

Para clasificar la percepción de los docentes se aplicó el análisis de conglomerados jerárquicos. Una vez obtenida la solución de conglomerados, se realizó una clasificación descriptiva basada en sus principales características. Cada conglomerado fue denominado de acuerdo a una categoría que agrupa conceptualmente el conjunto de elementos que los constituyen.

\section{Resultados y Análisis}

A partir del análisis de conglomerados jerárquicos, se identificaron cluster y categorías los que se describen en la tabla 2.

Tabla 2

Cluster y Categorías

\begin{tabular}{|c|c|}
\hline Cluster & Categorías \\
\hline \multirow{4}{*}{$\begin{array}{l}\text { 1. Orientación de la mejora en } \\
\text { espacios de innovación e } \\
\text { investigación educativa }\end{array}$} & a. Deficiencia en el proceso de investigación práctica \\
\hline & b. Innovación como proceso aislado \\
\hline & c. Cadena de investigación práctica desarrollada \\
\hline & d. Presencia de innovación pero ausencia de investigación \\
\hline \multirow[t]{4}{*}{ 2. Espacios de liderazgo } & a. Bajo nivel de liderazgo \\
\hline & b. Solo liderazgo directivo \\
\hline & c. Solo liderazgo pedagógico \\
\hline & d. Presencia de espacios de liderazgo \\
\hline \multirow[t]{4}{*}{$\begin{array}{l}\text { 3. Comunicación interna y } \\
\text { vinculación escuela-familia }\end{array}$} & $\begin{array}{l}\text { a. Bajo nivel de comunicación interna y de vinculación escuela- } \\
\text { familia }\end{array}$ \\
\hline & $\begin{array}{l}\text { b. Existencia de vinculación escuela-familia, pero bajo nivel de } \\
\text { comunicación interna }\end{array}$ \\
\hline & $\begin{array}{l}\text { c. Baja vinculación escuela-familia, pero buen nivel de } \\
\text { comunicación interna }\end{array}$ \\
\hline & $\begin{array}{l}\text { d. Alto nivel de comunicación interna y vinculación escuela- } \\
\text { familia }\end{array}$ \\
\hline \multirow{4}{*}{$\begin{array}{l}\text { 4. Creación de espacios para } \\
\text { innovación }\end{array}$} & a. Ausencia de espacios de innovación \\
\hline & b. Espacio de innovación sin soporte \\
\hline & c. Procesos de innovación no orientados \\
\hline & d. Presencia de espacios de innovación \\
\hline \multirow{4}{*}{$\begin{array}{l}\text { 5. Desarrollo personal y } \\
\text { perfeccionamiento }\end{array}$} & a. Bajo desarrollo personal y perfeccionamiento \\
\hline & b. Desarrollo personal pero sin perfeccionamiento \\
\hline & c. Existencia de perfeccionamiento sin desarrollo personal \\
\hline & d. Presencia de desarrollo personal y perfeccionamiento \\
\hline \multirow{3}{*}{$\begin{array}{l}\text { 6. Liderazgo directivo e } \\
\text { innovación }\end{array}$} & a. Bajo nivel de desarrollo \\
\hline & b. Liderazgo sin innovación \\
\hline & c. Procesos de innovación no orientados \\
\hline
\end{tabular}

Fuente: Análisis de conglomerados jerárquicos.

Encuesta aplicada a profesores de la región del Bío-Bío, Chile. 
A continuación se presenta un análisis por Cluster de acuerdo a 4 variables: género, formación académica, nivel educativo en el que habitualmente ejerce docencia y edad de los profesores encuestados.

\subsection{Orientación de la mejora en espacios de innovación e investigación educativa}

\subsubsection{Género}

El análisis diferenciado por género revela que hombres y mujeres se concentran en la categoría Deficiencia en el proceso de investigación práctica. En el sub-grupo de hombres, se destaca que un 15\% se ubica en el escenario ideal: Cadena de investigación práctica desarrollada. En el caso de las mujeres, esta cifra alcanza a 17\%. La categoría Innovación como proceso aislado, concentra un $28 \%$ y $24 \%$, para mujeres y hombres, respectivamente. Por lo tanto el género no es relevante en el desarrollo de la innovación y la investigación.

\subsubsection{Formación Académica.}

El sub-grupo de profesores encuestados con Licenciatura, alcanza un $36 \%$ en la categoría Deficiencia en el proceso de investigación práctica. En seguida, un $29 \%$ se encuentra en la categoría Innovación como proceso aislado. Finalmente, un 18\% y un 17\% se concentran en las categorías Presencia de innovación pero ausencia de investigación y Cadena de investigación práctica.

El sub-grupo de profesores/educador de párvulos, presenta un $41 \%$ en la categoría Deficiencia en el proceso de investigación práctica, mientras que un $31 \%$ se concentra en Innovación como proceso aislado. Cadena de investigación práctica desarrollada, sólo se presenta en un $14 \%$ de los casos.

A pesar de que una formación de postgrado podría favorecer el desarrollo de innovación e investigación, en el sub-grupo de profesores con grado de magister, y con estudios de diplomado, un $43 \%$ y un $52 \%$, respectivamente, se ubican en la categoría de Deficiencia en el proceso de investigación práctica desarrollada. Sólo un grupo de profesores con magister y diplomado realiza innovación en sus prácticas educativas y desarrolla investigación, orientando sus prácticas al mejoramiento de la calidad de la enseñanza.

Estos resultados dan cuenta de que la innovación y la investigación son prácticas poco frecuentes para una gran parte de los profesores encuestados. Los estudios de posgrado 
parecen fortalecer estas prácticas, pero no determinan un cambio de tendencia respecto a otros docentes.

\subsubsection{Nivel educativo en el que habitualmente ejerce docencia}

Se destaca que el mayor porcentaje de quienes se ubican en la categoría Cadena de investigación práctica desarrollada trabajan en Educación Media Técnico-Profesional y Científico-Humanista, con valores de $22 \%$ y $21 \%$, respectivamente. A nivel de preescolar, se destaca que un $40 \%$ se encuentra en la categoría de Innovación como proceso aislado, mientras que Deficiencia en el proceso de investigación práctica, alcanza un 37\% del total. A nivel de ciclo básico, de primero a cuarto básico y de quinto a octavo básico, se destaca que un $44 \%$ y un $46 \%$, respectivamente, se encuentran en la categoría Deficiencia en el proceso de investigación práctica. De igual modo, alrededor de un $13 \%$ se ubica en la categoría Cadena de investigación práctica desarrollada. Los resultados indican que uno de cada cinco docentes encuestados de la educación media desarrolla investigación; un resultado más alto, si se compara con el nivel básico.

El fenómeno más frecuente es la realización de prácticas de investigación o de innovación como procesos aislados; es decir, desvinculados de iniciativas de otros docentes y del contexto institucional. En este sentido, todos los niveles, pero en especial el ciclo básico, requiere de apoyo en su gestión institucional para introducir prácticas investigativas e innovaciones pedagógicas, lo que demandará formación continua y recursos focalizados.

\subsubsection{Edad}

En el sub-grupo de mayores de 50 años, se destaca que un $48 \%$ de los encuestados es clasificado en la categoría Deficiencia en el proceso de investigación práctica. La categoría Cadena de investigación práctica desarrollada se presenta en un 14\% de los encuestados de este sub-grupo.

En el sub-grupo de menores de 30 años, un 39\% se ubica en esta categoría Deficiencia en el proceso de investigación práctica. No obstante, un $21 \%$ es incluido en Cadena de investigación práctica desarrollada. Este dato revela que uno de cada cinco profesores jóvenes, están realizando algún tipo de trabajo investigativo, lo que sin duda, es un aspecto positivo para el mejoramiento de las prácticas docentes.

Los profesores de 31 a 40 años, presentan un 40\% en la categoría Deficiencia en el proceso de investigación práctica y que sólo un $11 \%$ pertenezca a la categoría Cadena de 
investigación práctica desarrollada representando la mitad del valor aproximadamente de los otros subgrupos etarios. Las categorías intermedias, Innovación como proceso aislado y Presencia de innovación pero ausencia de investigación, concentran un $25 \%$ de los profesores respectivamente. El sub-grupo de 41 a 50 años, se destaca por presentar un $42 \%$ de los profesores en la categoría Deficiencia en el proceso de investigación práctica. No obstante, un $20 \%$ se ubica en Cadena de investigación práctica desarrollada.

En resumen, los sub-grupos menores de 30 años y los de 41 a 50 años, obtienen la representación más alta en la categoría de mejor desempeño de este cluster - Cadena de investigación práctica desarrollada- uno de cada cinco profesores de estas edades desarrollan efectivamente procesos investigativos e innovaciones en sus aulas. No obstante, la categoría Deficiencia en el proceso de investigación práctica, reúne el mayor porcentaje de respuestas para cada una de las variables analizadas.

Los datos revelan que la evaluación y la orientación a la mejora se encuentra significativamente relacionada $(<0.01)$ a la innovación y a la investigación educativa. A nivel de cluster, los resultados indican que la categoría Deficiencia en el proceso de investigación práctica concentra a la mayoría de los encuestados, es decir, los procesos de innovación e investigación educativa se encuentran más bien ausentes de las prácticas docentes.

En el gráfico 1 se observa que la categoría mayoritaria es Deficiencia en el proceso de investigación práctica. En seguida, se destaca que en todas las variables analizadas es más frecuente la realización de innovaciones que de investigación. La cadena de investigación práctica desarrollada se encuentra más probablemente en profesores menores de 30 años/ o entre 41 y 50 años, que trabajan en la enseñanza media técnico-profesional y posean estudios de magister. 


\section{Gráfico 1}

Orientación a la mejora en espacios de innovación e investigación educativa

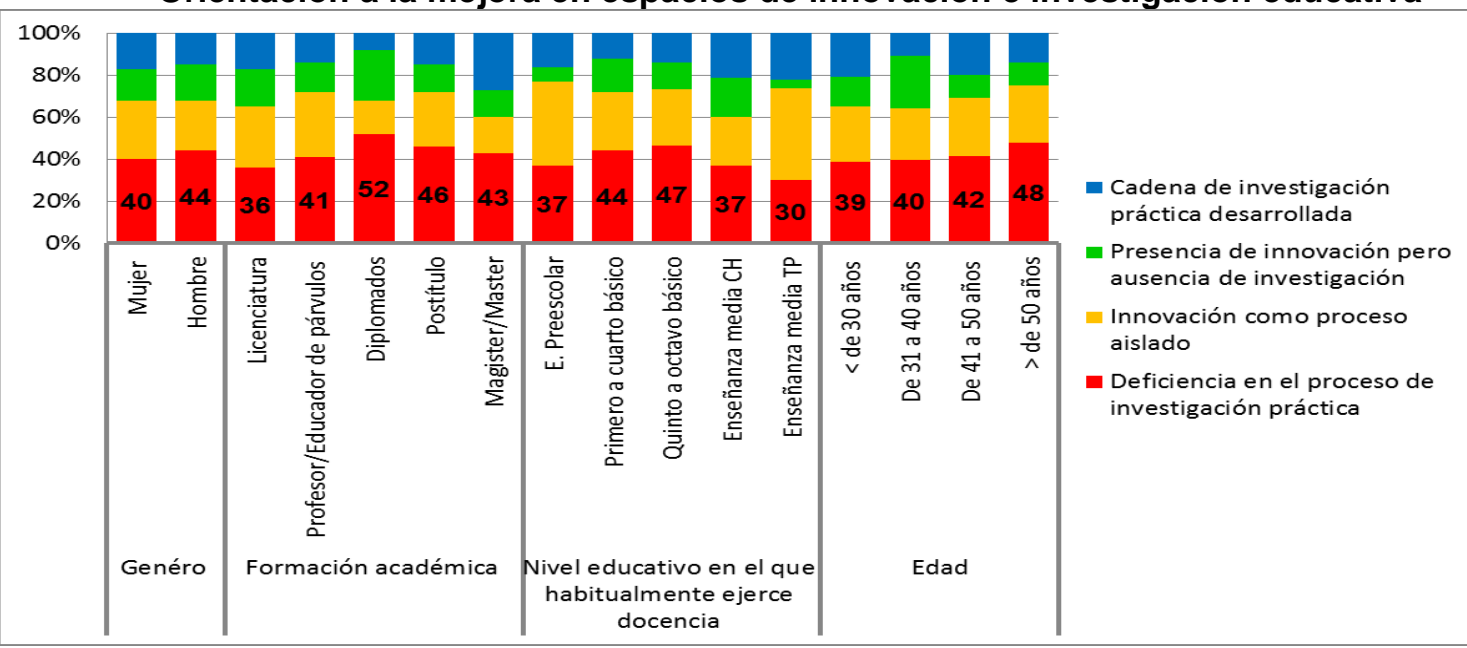

Fuente: Elaboración propia a partir de los datos generados del análisis de conglomerados jerárquicos.

\subsection{Espacios de Liderazgo}

\subsubsection{Género}

El análisis por género revela que tanto en el sub-grupo mujeres como hombres, siete de cada diez profesores, se ubican en la categoría Presencia de espacios de liderazgo. La categoría Solo liderazgo pedagógico alcanza cifras de $13 \%$ y $14 \%$ para el subgrupo de mujeres y hombres respectivamente.

\subsubsection{Formación Académica}

La categoría Presencia de espacios de liderazgo se manifiesta en más de un $60 \%$ de los profesores, en todos los niveles de formación académica. Profesor/Educador de párvulos y Postítulo alcanzan los porcentajes más altos en esta categoría: $72 \%$ y 75\%, respectivamente. Por otro lado, un $63 \%$ de los encuestados con grado de Magister, son incluidos en Presencia de espacios de liderazgo, lo que representa el porcentaje más bajo de todos los niveles de formación. En este caso, es posible, que los estudios de magister impliquen un aumento de conocimientos y estrategias de enseñanza-aprendizaje, pero, de acuerdo a estos resultados, no necesariamente favorecen las capacidades de liderazgo de los profesores. Futuras investigaciones podrían profundizar en los efectos de los estudios de magister en las capacidades de liderazgo. 


\subsubsection{Nivel educativo en el que habitualmente ejerce docencia}

En el nivel de primero a cuarto básico, se destaca que un $73 \%$ de los profesores se ubica en la categoría Presencia de espacios de liderazgo, similar porcentaje se da para los profesores que ejercen docencia en el nivel educativo de quinto a octavo básico (74\%). En educación pre-escolar, se destaca que un $65 \%$ de los profesores se encuentra en la categoría Presencia de espacios de liderazgo. A nivel de Enseñanza Media CientíficoHumanista, se destaca que un $68 \%$ se encuentra en la categoría Presencia de espacios de liderazgo.

En la Enseñanza Media Técnico-Profesional un 52\% de los encuestados se encuentra en la categoría Presencia de espacios de liderazgo, lo que representa el porcentaje más bajo en comparación a otros sub-grupos y en donde además la categoría Solo liderazgo pedagógico (26\%) tiene la mayor representatividad.

\subsubsection{Edad}

La categoría Presencia de espacios de liderazgo está presente en más del $60 \%$ de los profesores en todos los grupos etarios. Por otro lado, en el sub-grupo de profesores más jóvenes: menos de 30 años y entre 31 y 40 años la categoría Bajo nivel de liderazgo alcanza el $18 \%$, siendo la cifra más baja comparada con otros sub-grupos de edad. Se destaca que en el sub-grupo de profesores mayores de 50 años un $78 \%$ se ubica en esta categoría, un dato bastante importante, que requiere nuevas investigaciones, donde podría indagarse en la hipótesis que la experiencia docente se asocia al desarrollo del liderazgo pedagógico y directivo.

Los resultados muestran que el liderazgo directivo se encuentra correlacionado $(<0.01)$ con el liderazgo pedagógico. Como se observa en el Gráfico 2, en este cluster la categoría que expresa mejor el desarrollo del liderazgo- Presencia de espacios de liderazgorepresenta a la mayoría de los docentes: desde el 52\% en profesores de Enseñanza Media Técnico Profesional, hasta $78 \%$ en docentes mayores de 50 años. Este dato es relevante puesto que demuestra que el liderazgo pedagógico se combina con el liderazgo directivo en más del $50 \%$ de las diferentes categorías consideradas. 


\section{Gráfico 2 \\ Espacios de Liderazgo}

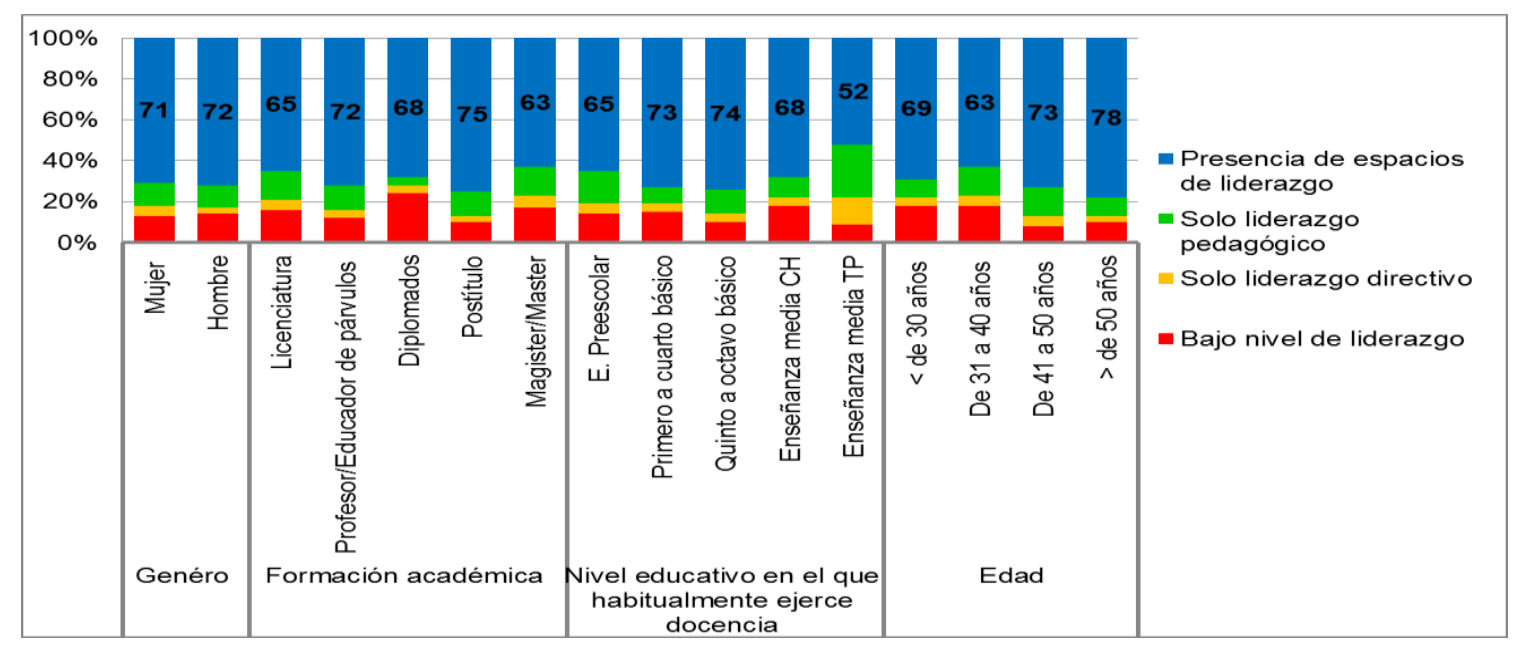

Fuente: Elaboración propia a partir de los datos generados del análisis de conglomerados jerárquicos.

\subsection{Comunicación interna y vinculación escuela-familia}

\subsubsection{Género}

La categoría Baja vinculación escuela-familia, pero buen nivel de comunicación interna concentra el $69 \%$ de los casos en los hombres y el $70 \%$ en las mujeres. La categoría ideal representada por un Alto nivel de comunicación interna y de vinculación escuela familia es alcanzada por el $13 \%$ y $14 \%$ de los hombres y mujeres respectivamente.

\subsubsection{Formación Académica.}

El análisis de la formación académica por sub-grupos, revela que entre un $68 \%$ y un $73 \%$ de los profesores, se ubican en la categoría Baja vinculación escuela-familia, pero buen nivel de comunicación interna. En el sub-grupo Licenciatura y Profesor/Educador de párvulos, se destaca que un $14 \%$ y $17 \%$ de los profesores, respectivamente, presentan un Alto nivel de comunicación y de relación escuela familia. El nivel de formación académica no parece ser un factor que determine de manera fundamental la comunicación y relación intra y extra escuela.

\subsubsection{Nivel educativo en el que habitualmente ejerce docencia}

La categoría Baja vinculación escuela-familia, pero buen nivel de comunicación interna, se manifiesta en el $75 \%$ de los profesores de primero a cuarto básico. Mientras que un $63 \%$ y 
61\% de los profesores de enseñanza media Científico-Humanista y Técnico Profesional se ubican en esta categoría. En educación pre-escolar, un 70\% de los casos se encuentra en la Categoría baja vinculación escuela-familia, pero buen nivel de comunicación interna, sin embargo es el subgrupo en el que la categoría Bajo nivel de comunicación interna y de vinculación escuela-familia alcanza el valor más bajo (7\%) en comparación los otros niveles educativos, mientras que en científico-humanista y técnico-profesional, presenta un 17\% en ambos. Nuevamente, los resultados por nivel educativo revelan que las dinámicas internas de cada uno implican diferencias en los cluster analizados.

\subsubsection{Edad}

Respecto a la edad, se destaca que entre el $66 \%$ y $76 \%$ de los profesores alcanzan la categoría Baja vinculación escuela-familia, pero buen nivel de comunicación interna. El subgrupo mayor de 50 años es el que tiene el mayor porcentaje representado en esta categoría. Los menores de 30 años y profesores entre 41 y 50 años presentan los mejores resultados en la categoría Alto nivel de comunicación interna y vinculación escuela-familia.

Los datos indican que la comunicación y la relación escuela-familia se encuentran correlacionados $(<0.01)$. Como puede observarse en el gráfico 3 , la categoría Baja vinculación escuela-familia pero buen nivel de comunicación interna concentra la percepción de los encuestados: con valores entre $61 \%$ y $76 \%$. A lo menos, para seis de cada diez encuestados la comunicación interna es fluida y es positivamente percibida; sin embargo, no ocurre así en el caso de la vinculación con la familia, lo que da cuenta de las dificultades de la relación de la institución escolar y los padres y apoderados. Este ámbito constituye un desafío tanto para los establecimientos escolares como para las universidades encargadas de la formación docente inicial y continua. 


\section{Gráfico 3 \\ Comunicación interna y vinculación escuela-familia}

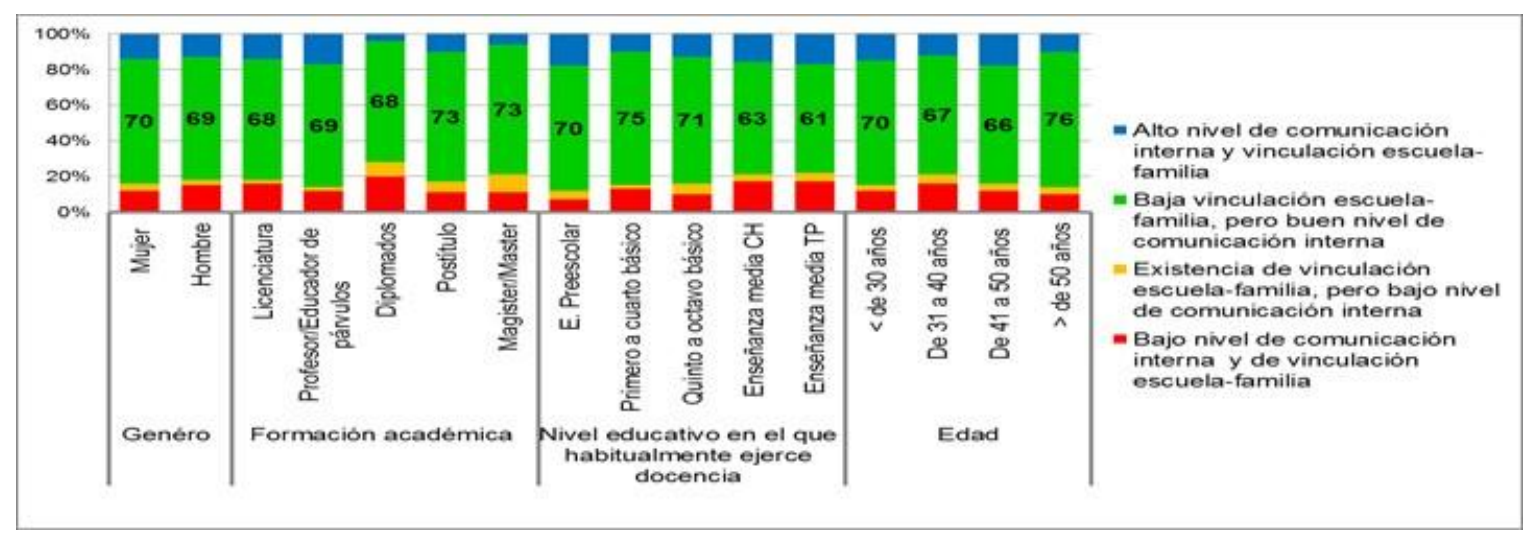

Fuente: Elaboración propia a partir de los datos generados del análisis de conglomerados jerárquicos.

\subsection{Creación de espacios para innovación}

\subsubsection{Género}

El análisis por género indica que un $67 \%$ de los profesores hombres son incluidos en la categoría Presencia de espacios de innovación, mientras que un 64\% de las profesoras se ubican en esta categoría. En ambos sub-grupos, la Ausencia de espacios de innovación se presenta en uno de cada diez encuestados.

\subsubsection{Formación Académica}

La Presencia de espacios de innovación se destaca como la categoría que concentra el mayor número de profesores. Sin embargo, según formación académica existen algunas diferencias. La formación de magister alcanza un 57\% en esta categoría, 10 puntos menos que, por ejemplo, aquellos docentes con título de profesor/ educador de párvulo, o con postítulo (67\%). En la categoría Procesos de innovación no orientados, se incluyen un $20 \%$ de profesores. Nuevos estudios podrían indagar en las causas de esta diferencia. Sin embargo, puede adelantar que podrían vincularse a una formación de magister con énfasis en aspectos más teóricos, como didácticas y evaluación, pero desvinculado de la incorporación de nuevas prácticas en el aula. 


\subsubsection{Nivel educativo en el que habitualmente ejerce docencia}

En el sub-grupo de enseñanza media científico-humanista y técnico profesional, se destaca que un $57 \%$ y un $65 \%$ respectivamente se incluyen en la categoría Presencia de espacios de innovación. En el nivel básico el $68 \%$ y el 70\% de los profesores de primero a cuarto y de quinto a octavo se incluyen en esta categoría. En nivel de pre-escolar, un $74 \%$ de los docentes son incluidos en la categoría Presencia de espacios de innovación. Estos resultados requieren de nuevos estudios que profundicen en las disposiciones de los docentes respecto a nuevas prácticas. Cabe preguntarse si la formación universitaria y posibilidades de formación continua tienen un impacto en las posibilidades de innovación. La edad, como se analizará a continuación, puede entregar nuevas pistas al respecto.

\subsubsection{Edad}

Se destaca que los Procesos de innovación no orientados son llevados a cabo por un $20 \%$ de los profesores menores de 30 años. Asimismo, un $60 \%$ de este grupo es incluido en la categoría Presencia de espacios de innovación. El escenario ideal, Presencia de espacios de innovación, representa al $71 \%$ de los mayores de 50 años. Es interesante notar que siete de cada diez encuestados mayores de 50 años, presenten prácticas educativas innovadoras, puesto que, en general, se asocia una mayor edad con menos capacidad de producir transformaciones y más apego al statu quo. Sería necesario investigar bajo qué circunstancias los profesores pueden innovar, y de este modo proyectar un modelo que propicie los espacios de innovación en el aula.

Los resultados indican que la innovación se encuentra correlacionada de manera estadísticamente significativa $(<0.01)$ tanto con la evaluación y orientación a la mejora como con el desarrollo personal. Como se observa en el gráfico 4, la categoría que congrega el mayor número de encuestados es la Presencia de espacios de innovación con valores entre $57 \%$ y $74 \%$. Los encuestados perciben la existencia de espacios de innovación en sus escuelas, lo que podría estar dando cuenta de la disposición de las autoridades escolares para desarrollar transformaciones en las prácticas docentes, así como la voluntad de los propios docentes para materializar cambios, lo que asimismo revela la posible incorporación de lineamientos del Ministerio de Educación, como el Marco para la Buena Enseñanza. En consideración de lo anterior, indagar en los procesos de desarrollo personal de los docentes puede entregar nuevos elementos a los análisis de innovación en el aula. 


\section{Gráfico 4 \\ Creación de espacios para innovación}

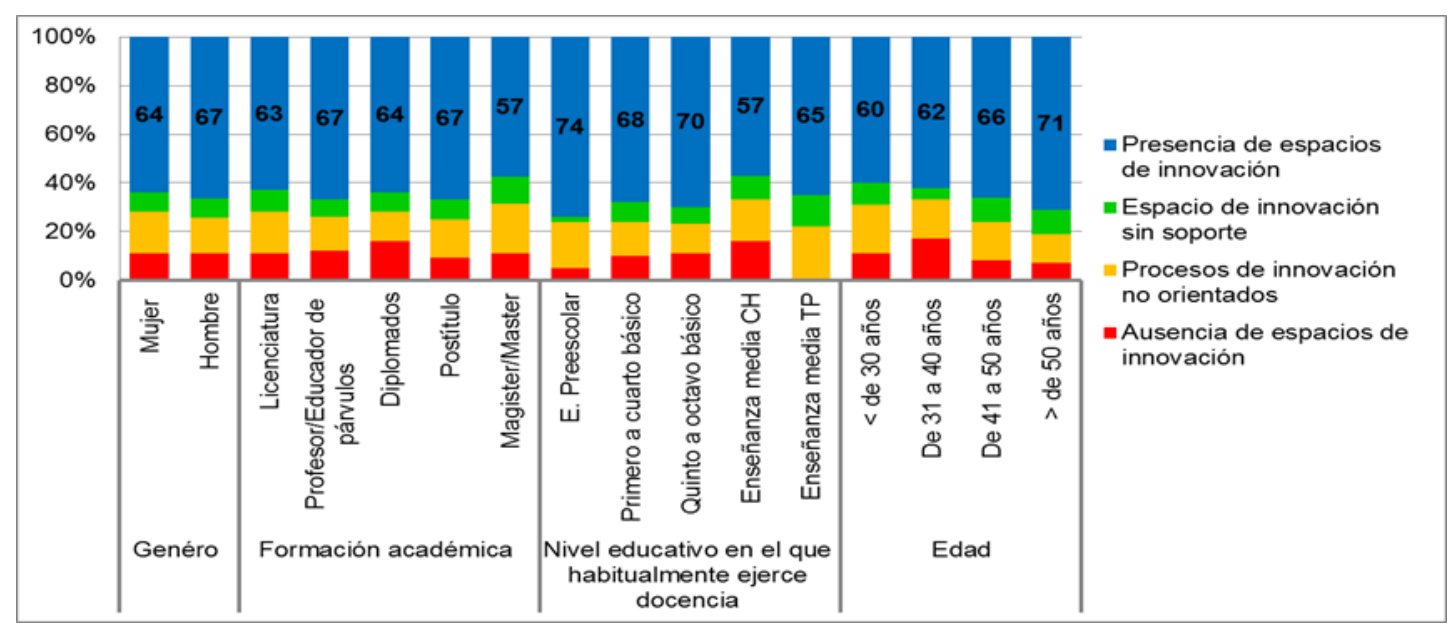

Fuente: Elaboración propia a partir de los datos generados del análisis de conglomerados jerárquicos.

\subsection{Desarrollo personal y perfeccionamiento}

\subsubsection{Género}

En análisis por género muestra que un $76 \%$ de las profesoras son incluidas en la categoría Existencia de perfeccionamiento pero no de desarrollo personal, mientras un $70 \%$ de los hombres se ubican en esta categoría. El escenario ideal Presencia de desarrollo personal y perfeccionamiento se manifiesta sólo en un $10 \%$ de las mujeres y un $6 \%$ de los hombres.

\subsubsection{Formación Académica}

Los sub-grupos de formación académica revelan que la categoría Existencia de perfeccionamiento pero no de desarrollo personal, representa entre un $68 \%$ y un $78 \%$ de los casos. Se destaca que un Profesor/Educador de párvulos y Licenciado alcanza un $72 \%$ y $73 \%$, respectivamente, en la categoría Existencia de perfeccionamiento pero no de desarrollo personal. En el caso de los profesores con Diploma o Postítulo, alcanzan cifras muy similares, en torno al $77 \%$.

Se destaca que aquellos profesores con magister, un $16 \%$ se ubica en la categoría Presencia de desarrollo personal y perfeccionamiento. Un $68 \%$ se ubica en la categoría Existencia de perfeccionamiento pero no de desarrollo personal. En este caso, las percepciones de los profesores, pueden estar marcadas por sus propias experiencias de 
desarrollo profesional a través de los estudios de magister, sin embargo, para una mayoría, estos estudios no se asocian al desarrollo personal.

\subsubsection{Nivel educativo en el que habitualmente ejerce docencia}

Se destaca que a nivel pre-escolar, nueve de cada diez profesores son incluidos en la categoría Existencia de perfeccionamiento pero no de desarrollo personal. Sin embargo, sólo un $2 \%$ se ubica en la categoría Presencia de desarrollo personal y perfeccionamiento. A nivel básico, de primero a cuarto básico y de quinto a octavo, se destaca que un $12 \%$ y un $10 \%$, respetivamente, se ubican en la categoría Presencia de desarrollo personal $y$ perfeccionamiento. A nivel de enseñanza media científico-humanista y técnico profesional un $11 \%$ y un $9 \%$ respectivamente están incluidos en la categoría Bajo desarrollo. Llama la atención, que un $22 \%$ de los profesores del nivel científico humanista se ubiquen en la categoría Desarrollo personal pero no perfeccionamiento, casi triplicando, por ejemplo, el caso de enseñanza de quinto a octavo básico. El mejor escenario, Presencia de desarrollo personal y perfeccionamiento, alcanza el valor más alto en el nivel educativo de primero a cuarto básico en el $12 \%$ de los casos.

Estos datos demuestran que el perfeccionamiento y desarrollo profesional es vivenciado de diferente manera de acuerdo al nivel educativo. Los docentes de primero a cuarto básico revelan mejores percepciones respecto a sus posibilidades de desarrollo profesional. Llama la atención que un $90 \%$ los profesores de pre-escolar releven la existencia de perfeccionamiento pero sin desarrollo personal. Estos datos podrían constituir la base de nuevas investigaciones, que indaguen, por ejemplo, en las condiciones laborales asociadas al desarrollo personal y profesional.

\subsubsection{Edad}

La categoría Existencia de perfeccionamiento sin desarrollo personal, representa el porcentaje más alto en todas las edades, casi tres de cada cuatro profesores, en todas las categorías. El escenario más complejo para el desarrollo profesional, Bajo desarrollo, se produce en un $8 \%$ y $9 \%$ de menores de 30 años y mayores de 50 años, respectivamente.

Profundizar en las razones de los profesores para decidir realizar un perfeccionamiento, así como en las causas que limitan la participación, ayudaría a crear programas de acuerdo a las necesidades de los profesores. Esto contribuiría a generar las 
facilidades, desde las escuelas y las universidades, para motivar la incorporación de los profesores en los programas de perfeccionamiento.

En el Gráfico 5 puede observarse que en todas las variables la categoría Existencia de perfeccionamiento sin desarrollo personal es la tendencia principal, concentrando entre un $62 \%$ y un $91 \%$ de los encuestados. Los docentes perciben que existen posibilidades de perfeccionamiento, las que, sin embargo, no posibilitan espacios de desarrollo personal, lo que podría restringir las potencialidades de los efectos positivos del perfeccionamiento, en las prácticas docentes.

Las correlaciones estadísticamente significativas $(<0.01)$ indican que el desarrollo personal está asociado a la pertinencia del perfeccionamiento. Los resultados indican que la tendencia principal se expresa en la categoría Existencia de perfeccionamiento pero no de desarrollo personal, lo que da cuenta de las limitaciones en las posibilidades de perfeccionamiento al que pueden acceder los profesores.

Futuras investigaciones podrían profundizar en tres ámbitos: 1) las variables que impactan en la percepción del desarrollo personal de los docentes en relación con los espacios de perfeccionamiento; 2) las causas de las diferencias de percepción por nivel educativo; y 3) la oferta de formación continua y su adecuación a la diversidad de contextos escolares, así como la formación de comunidades entre los docentes para compartir los conocimientos y prácticas aprendidos.

\section{Gráfico 5}

Desarrollo personal y perfeccionamiento

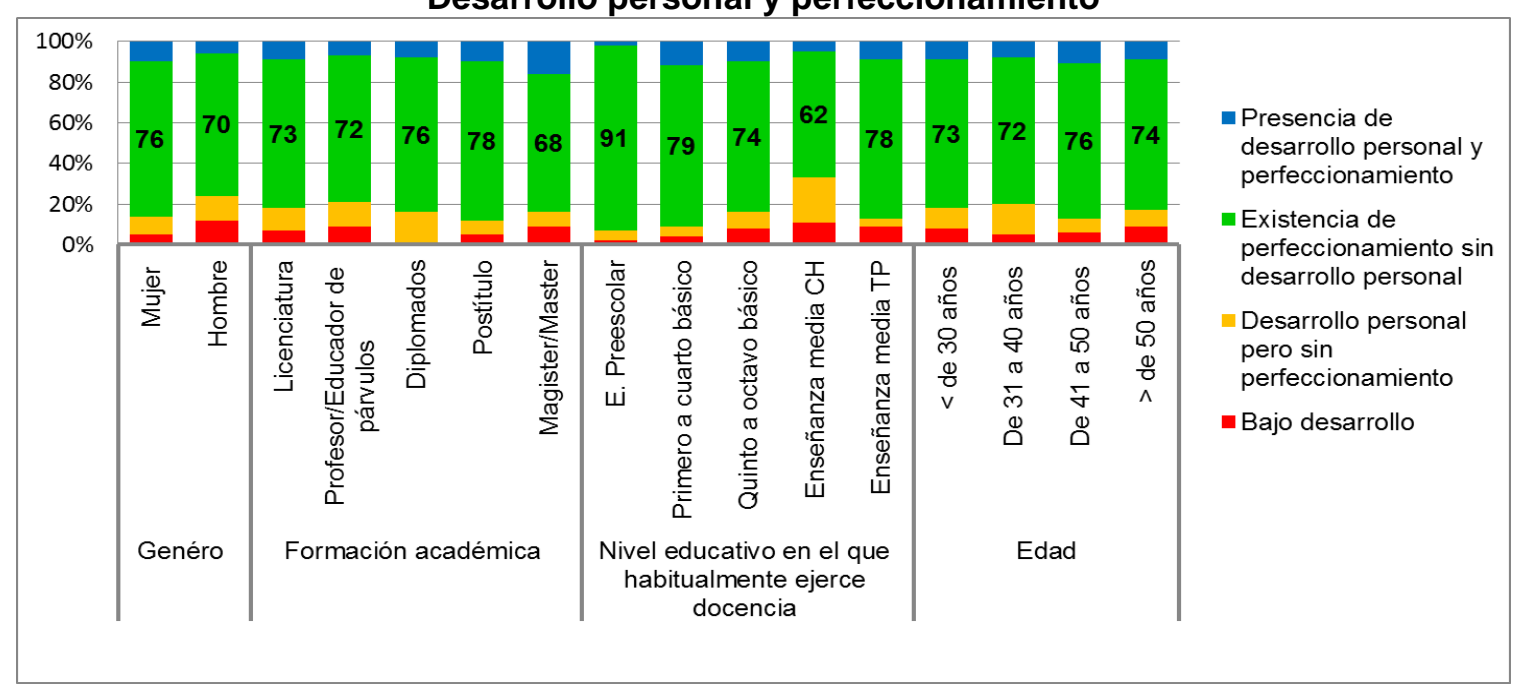

Fuente: Elaboración propia a partir de los datos generados del análisis de conglomerados jerárquicos. 
Imbernón (2011) refiriéndose al desarrollo profesional afirma que este:

Debe poner énfasis en el aprendizaje del profesorado y no tanto en su enseñanza. $Y$, por tanto, el desarrollo profesional se produce en el contexto de trabajo. Ese factor de la contextualización será fundamental en el desarrollo profesional ya que el desarrollo de las personas siempre tiene lugar en un contexto social e histórico determinado, que influye en su naturaleza. (p.12)

\subsection{Liderazgo directivo e innovación}

\subsubsection{Género}

El análisis del cluster liderazgo directivo e innovación indica que el escenario ideal, Liderazgo orientado a la innovación, es alcanzado por un $13 \%$ de hombres y $15 \%$ de mujeres. Por otro lado, la categoría Bajo nivel de desarrollo, se presenta en uno de cada diez encuestados según género. Procesos de innovación no orientados representa la tendencia principal: $70 \%$ y $69 \%$, en hombres y mujeres, respectivamente.

\subsubsection{Formación Académica}

En el mejor escenario, Liderazgo orientado a la innovación, a nivel de licenciatura y título de profesor/educador de párvulos aproximadamente un 15\% se ubica en la categoría Liderazgo orientado a la innovación. La categoría Diplomado congrega a uno de cada cuatro de profesores con este nivel de estudios.

En el sub-grupo de profesores que han realizado un Magíster/ Máster se destaca que uno de cada cinco se ubica en la categoría Bajo nivel de desarrollo. No obstante, un $11 \%$ es incluido en la categoría Liderazgo orientado a la innovación.

Estos datos llaman la atención respecto de los efectos de estudiar un magister sobre las posibilidades de ejercer un liderazgo directivo y de innovar en las prácticas educativas. Valdría la pena investigar si este fenómeno tiene relación con los contenidos de los programas o más bien se vinculan a un ambiente educativo propio del aula.

\subsubsection{Nivel educativo en el que habitualmente ejerce docencia}

A nivel pre-escolar, llama la atención que un $23 \%$ de este sub-grupo se encuentre en la categoría Bajo nivel de desarrollo, mientras que sólo un $7 \%$ se ubica en la categoría Liderazgo orientado a la innovación. A nivel de ciclo básico, tanto de primero a cuarto básico, como de quinto a octavo básico, se destaca que tres de cada cuatro profesores se ubican en 
la categoría Procesos de innovación no orientados. A nivel de enseñanza media se revela que un $16 \%$ se los profesores se encuentra en la categoría Liderazgo orientado a la innovación. La categoría Liderazgo sin innovación no se presenta en más de un 8\% de los encuestados por nivel educativo.

Como ya se ha mencionado, las políticas y programas que se diseñen para fomentar el liderazgo y las prácticas innovadoras en los centros escolares, requieren enfocarse según las particularidades de cada nivel educativo.

\subsubsection{Edad}

Por sub-grupos de edad, los mayores de 50 años concentran un $77 \%$ de profesores en la categoría Procesos de innovación no orientados. Además, presentan uno de cada diez profesores en la categoría Liderazgo orientado a la innovación. Llama la atención que en el grupo de profesores jóvenes, menores de 30 años, un 16\% se ubica en bajo nivel de desarrollo, la categoría de más bajo desempeño del cluster. En el grupo de edad de 31 a 40 años, se destaca que un $22 \%$ de ellos se encuentra en la categoría Liderazgo orientado a la innovación. Este dato revela cierta influencia de la edad en una actitud favorable a la innovación en las prácticas educativas. La edad de los profesores, pero también la experiencia, marca la forma de hacer y percibir los procesos de innovación pedagógica. Sería interesante indagar en los potenciales beneficios para los profesores menores de 30 años en la participación de un programa de mentoría, con profesores experimentados, que pudieran apoyarlos en su proceso de inserción laboral, mediante prácticas efectivas e innovadoras en el aula.

Las correlaciones estadísticamente significativas $(<0.01)$ indican, en primer lugar, la vinculación entre liderazgo directivo e innovación. Mientras que el liderazgo directivo y el liderazgo pedagógico están asociados positivamente a la evaluación y orientación a la mejora. Asimismo el liderazgo directivo está asociado a la evaluación de la gestión y a la gestión institucional e innovación. Cabe destacar que existe una correlación entre el liderazgo directivo y la comunicación $(<0.01)$, por lo que futuras investigaciones podrían analizar estas asociaciones en otros contextos.

Como puede observarse en el gráfico 6, la categoría más cercana al ideal, liderazgo orientado a la innovación, alcanza su mayor valor $24 \%$ en el sub-grupo de docentes con diplomados; seguido por docentes entre 31 y 40 años. La categoría de Procesos de innovación no orientados concentra entre el $60 \%$ y $77 \%$ de los encuestados. Estos 
resultados indican que, generalmente, los espacios de innovación son producidos como iniciativas puntuales, y desvinculados al liderazgo, por lo que carecerían de sustentabilidad en el tiempo, limitando así los efectos beneficiosos en las prácticas docentes.

Gráfico 6

Liderazgo directivo e innovación

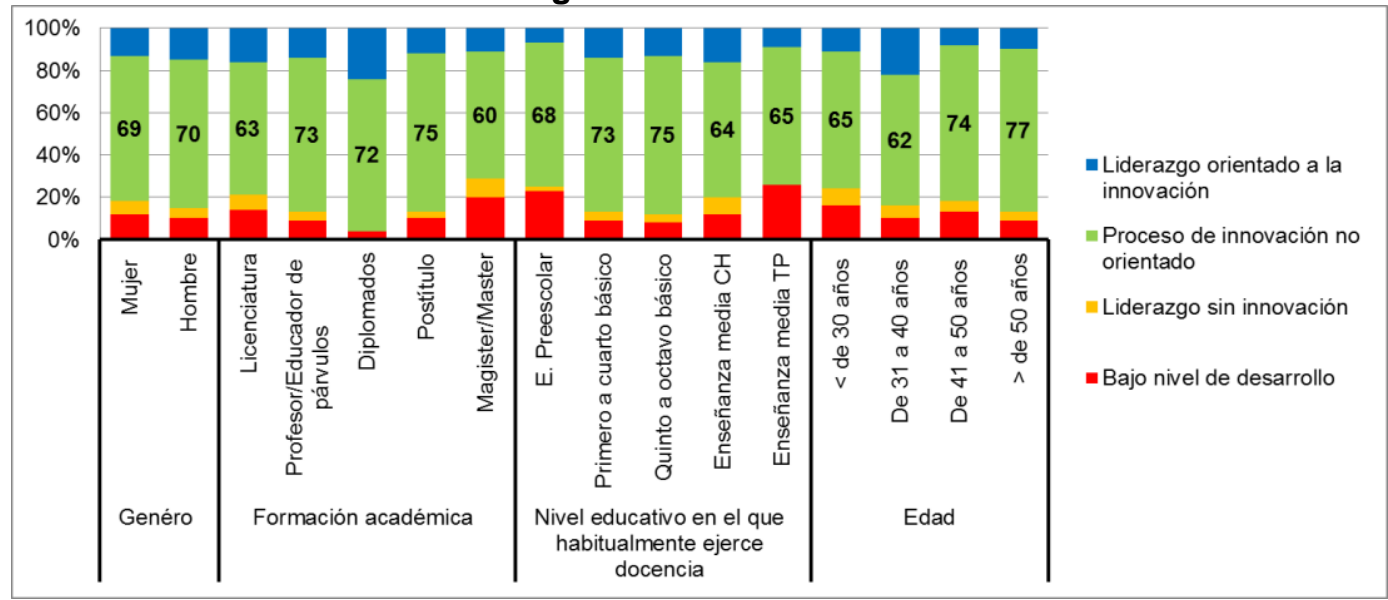

Fuente: Elaboración propia a partir de los datos generados del análisis de conglomerados jerárquicos.

\section{Conclusiones}

Los resultados revelan que parte importante de los docentes encuestados tienen la percepción de que la investigación y la innovación no son parte de sus prácticas educativas. Los profesores consideran que la investigación corresponde a un aspecto prácticamente ausente de las prácticas docentes de la escuela. Por su parte, la innovación se concibe como una instancia aislada y desvinculada del quehacer docente y que no responde a un proceso de planificación orientado al logro de objetivos a largo plazo.

Los datos obtenidos revelan procesos disímiles por nivel educativo. El ciclo básico requiere de apoyo en su gestión institucional para introducir prácticas investigativas e innovaciones pedagógicas, lo que demandará formación continua y recursos focalizados.

En cuanto a la formación recibida, sólo un grupo de profesores con magister y diplomado innova en sus prácticas educativas y realiza investigación, orientando una mejora en la calidad de la enseñanza. Este elemento necesita ser estudiado con más profundidad puesto que los programas de magister y de diplomado parecen no estar entregando elementos potenciadores de prácticas innovadoras y de investigación. Para ello sería necesario, entre otras acciones, analizar el perfil de egreso y los contenidos de los programas de magister y de diplomado que se ofrecen en las instituciones de educación 
superior. Asimismo, sería necesario indagar en las formas de gestión institucional que favorecen el desarrollo de innovación e investigación, y evitando el repliegue del proceso escolar sólo a aspectos tradicionales de la práctica educativa.

Respecto de los espacios de liderazgo, se observa que los docentes perciben, en su mayoría, la existencia de espacios de liderazgo en sus escuelas, un liderazgo que se ejerce a nivel pedagógico y directivo. La tendencia es similar en todas las variables analizadas, género, edad, nivel en el que ejerce docencia y formación recibida. Por lo tanto, se destaca como un elemento positivo desde la percepción docente. Entre los grupo etarios analizados los mayores de 50 años son quienes perciben con mayor fuerza la presencia de liderazgo en sus establecimientos.

Los espacios de liderazgo y de innovación se encuentran aún en fase de consolidación, de acuerdo a los docentes encuestados. Los procesos de innovación carecen de objetivos definidos por un liderazgo que brinde las orientaciones necesarias para transformarse en fuente de cambio institucional. Se considera necesario investigar sobre las comunidades escolares y las maneras de ejercer liderazgo.

Los datos revelan que la presencia de espacios de liderazgo se conjuga con una baja vinculación escuela-familia, pero buen nivel de comunicación interna. Esto implica una buena comunicación entre profesores, pero una vinculación con los padres y apoderados que aparece como poco desarrolla. Es necesario indagar en las causas y en las consecuencias de la baja vinculación escuela-familia. Estudios realizados por Cornejo y Redondo (2001) concluyen que los alumnos de enseñanza media presentan una mejor percepción de clima escolar cuando existen mejores condiciones de participación, lo que incluye que se considere las opiniones de padres y apoderados. En este caso, se recomienda realizar nuevas investigaciones o intervenciones de acuerdo al modelo de investigación-acción, donde se potencie la comunicación externa, haciendo partícipe a la familia en la comunidad escolar.

El análisis de los datos revela que los profesores requieren de capacitación para potenciar las capacidades comunicativas, en particular, con la familia de los estudiantes. Esto implica el desarrollo tanto de conocimientos como de estrategias concretas que posibiliten espacios de intercambio entre alumnos, profesores, padres y apoderados, lo que redunda en la formación de una comunidad educativa preocupada por el aprendizaje de todos sus alumnos. 
Desde la perspectiva del desarrollo profesional, los resultados muestran que los profesores perciben que no existe un desarrollo profesional en coherencia con el desarrollo personal. Es necesario efectuar análisis pormenorizado para determinar si la oferta de programas de perfeccionamiento es pertinente para los requerimientos de estos profesores, considerando también los contextos sociales de los propios docentes y sus estudiantes.

Los datos analizados en relación a las variables del estudio, demuestran que el perfeccionamiento y desarrollo profesional es vivenciado de diferente manera de acuerdo al nivel educativo, sobresaliendo en la educación prebásica la perspectiva de que el perfeccionamiento no va acompañado por un desarrollo personal. Por ello se recomienda indagar sobre la necesidad de diferenciar el perfeccionamiento docente por nivel educativo, focalizándose a un nivel educativo. Aquello, además, requiere un profundo análisis de necesidades del centro escolar, así como de los actores involucrados en el proceso de enseñanza-aprendizaje. Profundizar en las razones de los profesores para decidir realizar un perfeccionamiento, así como en las causas que limitan su participación, ayudaría a crear programas de acuerdo a las necesidades de los profesores. Esto contribuiría a generar las facilidades, desde las escuelas y las universidades, para motivar la incorporación de los profesores en los programas de perfeccionamiento.

Los resultados indican que un grupo de docentes se ubica en un estado caracterizado por instancias de perfeccionamiento restringido y desvinculados de su desarrollo personal, en un contexto de carencia de investigación y de innovación con objetivos a largo plazo.

Los análisis de percepción permiten relevar aquellos temas que pueden constituir nudos críticos para el ejercicio docente. Por esto, nuevas investigaciones replicadas en otras regiones de Chile contribuirán a determinar si los resultados obtenidos pueden ser generalizados o si, en cambio, son eventos que responden a dinámicas específicas.

\section{Referencias}

Anderson, Stephen. (2010). Liderazgo directivo: claves para una mejor escuela. Psicoperspectivas, 9(2), 34-52.

Aravena, Marcela, Kimelman, Eduardo, Micheli, Beatriz, Torrealba, Rodrigo y Zúñiga, Javier. (2006). Investigación Educativa I. Santiago de Chile: Universidad ARCIS y AFEFCE.

Baron, Robert y Byrne, Donn. (2005). Psicología social. México: Pearson. Prentice Hall.

Bolívar, Antonio. (2010). El liderazgo educativo y su papel en la mejora: una revisión actual de sus posibilidades y limitaciones. Psicoperspectivas. Individuo y Sociedad, 9(2), 933. 
Carr, Wilfred. (1996). Una teoría para la educación. Hacia una investigación educativa crítica. Madrid: Morata.

Cisternas, Tatiana. (2011). La investigación sobre formación docente en Chile. Territorios explorados e inexplorados. Calidad en la educación, (35), 131-164.

Clark, Christopher y Peterson, Penélope. (1989). Procesos de pensamiento de los docentes. En Merlin Wittrock (Ed.), La investigación de la enseñanza III (pp. 443-539). Barcelona: Paidós.

Contreras, José. (1996). Teoría y práctica docente. Cuadernos de pedagogía, 253, 92-99.

Contreras, José. (2010). Ser y saber en la formación didáctica del profesorado: una visión personal. Revista Interuniversitaria de Formación del Profesorado, 68(24,2), 61-81.

Cornejo, Rodrigo y Redondo, Jesús. (2001). El clima escolar percibido por los alumnos de enseñanza media: Una investigación en algunos liceos de la Región Metropolitana. Última década, 9(15), 11-52.

Cornejo, Rodrigo. (2006). El experimento educativo chileno 20 años después: una mirada crítica a los logros y falencias del sistema escolar. Revista Electrónica Iberoamericana sobre Calidad, Eficacia y Cambio en Educación, 4(1), 118-129.

Ezpeleta, Justa. (2004). Innovaciones educativas. Reflexiones sobre los contextos en su implementación. Revista Mexicana de Investigación Educativa, 21, 403-424.

Fullan, Michael y Hargreaves, Andy. (1997). ¿Hay algo por lo que merezca la pena luchar en la escuela? Morón: Sevilla.

Hernández, Roberto, Fernández, Carlos y Baptista Pilar. (2008). Metodología de la investigación. México D.F.: Mcgraw-Hill.

Imbernón, Francisco. (2011). Un nuevo desarrollo profesional del profesorado para una nueva educación en el siglo XXI. Revista Educação Skepsis, (2), I-XX.

Imbernón, Francisco. (2012). Un nuevo desarrollo profesional del profesorado para una nueva educación. Revista de Ciencias Humanas, 12(19), 75-86.

Magendzo, Abraham. (2000). Investigación de la práctica pedagógica en el contexto de las reformas curriculares. Memoria del Simposio Internacional de investigadores en educación "La investigación como práctica pedagógica". Santa Marta, Colombia 8-10 de noviembre de 1999, 65-78. Bogotá: Convenio Andrés Bello.

Marcelo, Carlos (2009). Los comienzos en la docencia: un profesorado con buenos principios. Profesorado. Revista de currículum y formación del profesorado, 13(1), 1 25.

Organización para la Cooperación y Desarrollo Económico (OCDE). (2009). Creating Effective Teaching and Learning Environments: First Results from TALIS. Recuperado del sitio http://www.oecd.org/TALIS 
Ortega, Pedro, Ramírez, María Eugenia, Torres, José Luis, López, Ana, Servín, Citlati, Suárez, Lilliana., y Ruiz, Blanca. (2012). Modelo de innovación educativa. Un marco para la formación y el desarrollo de una cultura de la innovación. RIED. Revista iberoamericana de educación a distancia, 10(1), 145-173. Recuperado del sitio http://www.biblioteca.org.ar/libros/142346.pdf

Pérez Gómez, Ángel. (2010). Aprender a educar. Nuevos desafíos para la formación de docentes. Revista Interuniversitaria de Formación de Profesorado, 24(2), 37-60.

Rodríguez, José y Castañeda. Elsa (2001). Los profesores en contextos de investigación e innovación. En Revista Iberoamericana de Educación, 25, 103-146. Recuperado del sitio: http://www.rieoei.org/rie25a05.htm

Tapia-Gutiérrez, Carmen, Becerra-Peña, Sandra, Mansilla-Sepúlveda, Juan, SaavedraMuñoz, July. (2011). Liderazgo de los directivos docentes en contextos vulnerables. Educación y educadores, 14(2), 389-409.

Vander Zanden, James (1990). Manual de psicología social. Madrid: Paidos Iberica

Vezub, Lea. (2007). La formación y el desarrollo profesional docente frente a los nuevos desafíos de la escolaridad. Revista de currículum y formación del profesorado, 11(1), $1-23$. 